"venture to think the services of the nurses were also of a most valuable kind; at any rate, comfort is songht for Mr. Murphy in the result of the investigation, which shows only 7.6 per cent. of the cases to be possibly attributable to school influence, "a complete justification of the position which he has assumed" being found therein. One is tempted to ask, what about the origin of the remaining trifle of 92.4 per cent. of the cases? That the schools are not to blame for the great increase of diphtheria in London I am convinced, and the sooner we abandon this unstable view and set to work to find out the real cause the better for science and the better for the metropolis.

$$
\text { I am, Sirs, yours faithfully, }
$$

June 8th, 1896.

WILLIAM R. SMith, M.D. Aberd.

** The space at our disposal does not permit us to do more than comment briefly on the matter referred to in Dr. Smith's letter. We must be pardoned if we have assumed that his report is intended as a reply to the reports of Mr. Shirley Murphy, seeing that of the pages in Dr. Smith's report which we can regard as relevant to the subject of the influence of schools on diphtheria prevalence at least three-quarters are devoted to a criticism of Mr. Murphy's two points-(1) the change in the age incidence of diphtheria mortality since 1870 ; and (2) the reduction in the number of notified cases of diphtheria at the time the London board schools are closed for the summer holidays. Dr. Smith's remarks concerning the comparisons of the decades 1871-80 and 1881-90 make it evident that he still fails to see that a change effected in the main in the decade 1871-80, and conspicuous when comparison is made between 1861-70 and 1871-80, need not (to meet the school hypothesis) be again conspicuous between 1871-80 and 188190. We pass by Dr. Smith's incomprehensible reference to a "somewhat adroit manipulation of figures" by the writer of our article "to enable him to escape from the difficulty in which he finds himself." The table in Dr. Smith's letter leads us to the conclusion that he is now prepared to abandon the position he assumed in his report when he wrote " that while the percentage of children attending elementary schools has largely increased-viz., from 24.8 per cent. in 1871 to 59.8 per cent. in 1893 - the comparative death-rate at ages three to ten has remained throughout these years fairly constant." As Dr. Smith now evidently sees, it has done nothing of the sort; but, as we pointed out in our article, "with increase of school attendances there has been a gradual increase of comparative diphtheria mortality at the school ages." In studying these figures there is, however, another consideration which must be held in view, and that is that the diphtheria rate at $3-10$ compared with all ages does not make evident the whole story of the increased incidence of the diphtheria rate on that age. The result is masked and greatly minimised by the fact that the deaths from 3-10 constitute a very large proportion of the deaths at all ages. The comparison, therefore, between the increase of 11.1 per cent. in the comparative death-rate and the increase of 81.6 per cent. in the proportion of the children attending school is absurd. How much of the increase in the death-rate at all ages is due to increased school attendance still remains unknown, and certainly we are not prepared to accept Dr. Smith's 7.6 per cent. of the cases at school age as including anything like all which are "possibly attributable to school influence." Dr. Sraith concludes his letter by stating that "schools are not to blame for the great increase of diphtheria in London." We challenge him to refer us to the statement of any person who has said they are. There is a wide difference between the position which regards schools as contributing in important degree to this increase and that which regards schools as the sole factor in such increase. All the evidence at present available points to the inaccuracy of Dr. Smith's conclusion that school influence "plays but an unimportant part" in the increase.-ED. L.

\section{THE CASE OF MR. LIONEL SMITH.} To the Editors of THE LANCET.

SIRs,--Will you allow me through your columns to thank those gentlemen who so kindly came forward to assist me out of the difficulties in which I was placed by the action of the West Australian Government? I have now reached my new home and I hope to make a fresh and successfu start in life which, but for the generous aid accorded me, I should have been unable to accomplish.

I am, Sirs, yours faithfully, H. LIONEL SirTH.

N'Qutu, Zululand, South Africa, May 11th, 1896.

\section{ISOLATION AND THE PUBLIC HEALTH ACT,}

\section{To the Editors of THE LANCET.}

SIRs,-The following matter, which I will put as briefly as possible, may be of interest and use, perhaps, to some of your readers. Since the introduction of "notification" by the Public Health Act (London), 1891, I have had some trouble with the sanitary authority of this parish of St. George, Hanover-square. During this period it has been the custom to remove as many as possible of the cases of scarlet fever and diphtheria to the Metropolitan Asylums Board Hospitals. Certain cases, however, which I have me with in my practice $I$ have decided, for reasons stated below, to retain and attend at their own homes, and have expressed to the patients' relatives my approval that they should so remain, provided that my directions as to isolation and treatment were faithfully carried out, and therefore they could remain. Notwithstanding this, and knowing that I had expressed this opinion, the sanitary inspector has stepped in, has insisted on the patients being removed to the hospital and they have been so remored, the grounds given for this action being that the patients were not properly isolated in his opinion.

The cases in question were mostly scarlet fever or diphtheria, occurring in families occupying generally three or four, sometimes only two, rooms; but in each case the patient was put into a separate room from the rest and confined there without any direct communication with other members of the family, the only person going backwards and forwards at all from the sick room being the nurse-usually, of course, the child's mother-whom I made take sufficient precautions against spreading the disease. I have attended many such cases in pre-notification years and have nerer known the disease to spread after such isolation has been established in any case. Now the question of what is proper isolation is, I maintain, essentially a medical question, and it is intolerable that an unqualified person, such as a sanitary inspector, should be allowed to override the opinion of a medical man on a medical question or to interfere with his patients, nor is it professionally correct for a medical officer of health to disregard the opinion of another medical man. I complained more than once to the medical officer of health (Dr. Corfield), but he supported the sanitary inspector and the offence was repeated. The Public Health Act is not very definite on the matter; but as it declares that any legally qualified medical practitioner may certify that an infections patient has not proper accommodation one would suppose (and this seems to agree with common sense) that he would be equally able and entitled to certify the obverse-viz., that an infectious patient was properly accommodated and isolated. I therefore wrote to the Local Government Board last February, stating the case and giving particulars, and asked for an authoritative opinion. The Local Gorernment Board corresponded with the sanitary authority of St. George's, Hanover-square, and replied to me on the 2 nd inst., enclosing a copy of the Board's final reply to the Vestry, as follows:-

Local Government Board, Whitehall, S.W., March 28th, 1896. To the Clerk of the Vestry, St. George's, Hanover-square. SIR,-I am directed by the Local Government Board to acknowledge the receipt of your letter of the 18th inst. enclosing a copr of a report which the Vestry of the Parish of St. George, Hanover-square, have receivel from their medical officer of health respecting the complaint of Dr. Benbam, and in reply I am to state that whilst the Board concur with the riew expressed by the medical officer of health as to the desirability of securing isolation in hospital of such cases of the infectious fevers as are referred to in his report, they are of opinion that where a medical practitioner is known to be in attendance on any such case, removal to hospital by the officers of the sanitary authority 
should not be effected without some communication either at the time or immediately after the removal, with the medical practitioner in question. I am, Sir, your obedient servant

A. D. AnRIAN, Assistant Secretary.

I hope that there will now be no further friction over this subject. The principal reasons I have had for retaining such patients at home are these:-1. The parents of the child often wish it. 2. It is part of the duty of a medical man to attend such cases. 3. It is very unjust, although it may be legal for the ratepayers to bear the entire cost of maintenance and treatment, even though the relatives could afford to pay. 4. Patients are longer in recovering if treated at the hos pitals - at any rate, they are always detained there, I believe, for ten weeks at least, whereas they can be got well almost always in about six weeks if treated at home. 5 . I believe, though it would be difficult to demonstrate it. that cases of scarlet fever have a better chance of recovery and avoiding complications-e.g., diphtheritic sore-throat at a late stageif treated at home. 6 . It is a very easy matter to isolate cases of scarlet fever and diphtheria. By strictly observing a few simple precautions there is scarcely any risk, according to my experience, of the infection spreading. Surely as a matter of fact most cases of scarlet fever arise from infection by slight and unnoticed cases and most of the rest from imperfect disinfection of clothes, furniture, \&c.

I think that it has yet to be proved that the adoption of notification and the removal of every detected case to a fever hospital have any material effect in lessening the prevalence and spread of scarlet fever in London, and what chance is there of stamping the disease out? The question is one of interest and importance, especially considering the enormous cost of the Metropolitan Asylums Board hospitals and the extravagant rise of the rates which the over-burdened ratepayers have to pay. And yet some enthusiasts are beginning to talk of removing cases of measles to fever hospitals. What next? I am, Sirs, yours faithfully,

F. LuCas BenhaM, M.D. Lond.

Elizabeth-street, Eaton-square, S.W., June 8th, J396.

\section{"THE REGIS'TRATION OF MIDWIVES." To the Editors of THE LANCET.}

SIRs,-I willingly accept Mr. Humphreys' corrections, although I would have imagined that the term "Midwives Institute and its Supporters" as employed by me was sufficiently comprehensive to have included the Midwives Bill Committee. The Local Government Board will perhaps be able to find time for drawing up a code of instructions for the guidance of midwives, as the sanitary portion of these should be an easy day's work for a specialist in that department of knowledge, and the post-office provides a very simple and expeditious means of communication with the local medical officers of health. I am pleased to learn that the Privy Council imported itself into the administration of the Midwives Registration Bill and so provided a good example of unconscious humour, although $\mathbf{I}$ would regret to be placed under the necessity of believing $\mathrm{Mr}$. Humphreys capable of anything of that kind. "The rights of existing midwives" do, however, seem to me a rather uncertain quantity, and I am afraid that the legal formulation of these would more than exhaust the resources of even a Philadelphia lawyer, had he the courage to make the attempt. If progress is the development of order it is perhaps desirable that the profession should try to create a little order in the matter now under consideration. I am, Sirs, yours faithfully,

Salford, June 6th, 1896. WILLIAM Fraser.

\section{"THE CHILDREN OF THE STATE." To the Editors of THE LANCET.}

SIRS, - The report of the Departmental Committee on Poor-law schools having received notice in THE LANCET, allow me to draw attention to certain statements and recommendations in that report which bear my name in the margin, but which are not in accord with my evidence thus referred to and which I cannot approve. In 1890-91 I examined individually 9831 children in Poor-law district and separate schools for a joint committee of the Charity Organisation Society and the British Medical Association, who presented a report embodying those obserrations to the President of the Local Government Board at his request in June, 1892. At the request of the Departmental Committee I gave evidence from published records as to the chilaren I had seen. This showed that 15.0 per cent. of the boys and. 12.2 per cent. of the girls presented some degree of congenital developmental defect predisposing them to low health with mental dulness. In the departmental report conditions found among the children are mainly ascribed to their environment in aggregation, sanitation, and education. Eridence showed that great care in selecting children for boarding-out was necessary ; only perfectly normal children should be placed in the less protected position. 'This would necessarily leare all the cases of derelopmental defect in the schools. With regard to the "feeble-minded children" I was asked my experience of the best methods of training, and in reply referred to patients who paid $£ 100$ to $£ 150$ a year for living and training in private families. This exidence is referred to as a ground for recommending that pauper children feeble mincled should be boarded out - a proceeding that, in my opinion, would be unwise and unfair to the child. Under the heading "Feeble-minded Children Attending Public Elementary Schools" the com. mittee say: "3\&2. When boardel out or placed in small homes the children attend public elementary schools" ; my name is again given in the margin, but does not refer to evidence in support of the statement; I am not aware that feeble-minded children hare been boarded out. A statement in the form of a question was made by a member of the committee as to the number of children who required special training at the Mile-end Schools; I did not agree with that statement; the question in place of $w y$ reply is inserted in a paragraph of the report. Other points might be mentioned to which exception may be taken; but enough has beer said to show that before accepting the conclusions of the report the scientific and medical evidence needs to be com. pared with the statements and recommendations made. I am, Sirs, yours faithfully,

Kensington, W., June 6th, $1895 . \quad$ FRANCIS WARNER.

\section{THE FREE HOME FOR THE DYING : THE NELSON BED.}

To the Editors of THE LANCET.

SIRs, - We ask those who take an interest in the seafaring class to lend us a hand in keeping up this bed in the Free Home for the Dying. There being no paid staff at the Home all donations are for the benefit of the inmates. Last year kind friends contributed $£ 78$ 15s., and we now ask for five shillings from all who can afford it, which will provide for the wants of this real charity for this year. Postal orders may be sent to the honorary secretary, at the office, 281 , Strand, W.C., or to the bankers, Messrs. Hoare and Co., 37, Hleet-street, E.C.

We are, Sirs, yours faithfully,

W. PoRmLock-DADsos, Captain, Honorary Secretary.

William HoARE, Honorary Treasurer. Jume 18th, 1896.

\section{"INDURATED PSEUDO-CHANCRES."}

To the Editors of THE LAxCET.

SIRs,-Conclusions Nos. 4 and 5 in MIr. A. Shillitoe's paper I thoroughly agree with if the expression "spontaneously": be omitted. The experience of one case in private practice and a few in prison work has taught me that a sore may appear on the place where a chancre bas been due to the irritation of masturbation; and, further, that this sore may have a for-all-the-world resemblance to a fresh chancre, and yet that it will not be followed by true secondary symptoms. - I am, Sirs, yours faithfully,

Canterbury, May 30th, 1896.

PCGIX THORNTOX.

\section{"A DECEPTIYE ETHEI INHALER." To the Editors of THE LAXCET.}

SrRs,-We notice in TII LAXCEI of June 6 th a letter from Messrs. Mayer and Meltzer disclaiming any connexion with a Clover"s inhaler with transposed viscera, mentioned by Mr. MI. S. Paul of Nagasaki, Japan, as having come under his notice. As we are jus now advertisirg a Clover s ether inhaler we should be glad if you would incert this letter to the effect that the inhaier mentioned by $\mathrm{NIr}$. Paul is nut one of our making, as your readers might think from Hessrs. Mayer and Meltzer s letter, which says nothins about it being. 